\title{
Correction to: Optimization of Process Flowsheets through Metaheuristic Techniques
}

José María Ponce-Ortega and Luis Germán Hernández-Pérez

\section{Correction to:}

J. M. Ponce-Ortega, L. G. Hernández-Pérez, Optimization of Process Flowsheets through Metaheuristic Techniques, https://doi.org/10.1007/978-3-319-91722-1

Book was originally published with inaccessible ESM links; Link has been updated. 